không bi ép, và trở lại vị trí bình thường, ủng hộ cho việc phẫu thuật tuổi sơ sinh [8].

Chúng tôi sử dụng mảnh ghép phía sau xương ức và chỉ tiêu Safil để kết hợp tạo hình xương ức với 3 trẻ mắc $\mathrm{SC}$, với 2 trẻ mắc $\mathrm{SC}$ hoàn toàn được mổ tuổi sơ sinh và và 1 trẻ có SC chữ V ngược được mổ chữa lúc 12 tháng tuổi, cả 3 trẻ đều phục hồi được giải phẫu và chức năng xương ức, liên xương vững, không có biến chứng.

\section{KẾT LUÂN}

Khe hở xương ức là một bệnh lý hiếm gặp. Đánh giá tổn thương phối hợp và phẫu thuật sớm quanh tuổi sơ sinh thuận lợi hơn, sử dụng Omnipore trong phẫu thuật kết hợp xương ức cho kết quả liền xương vững và không có biến chứng, đặc biệt các trường hợp diện khe hở xương ức lớn. Như vậy, ứng dụng Omnipore trong tạo hình xương ức ở trẻ em có khe hở xương ức là khả thi, tuy nhiên cân có nghiên cứu với nhiều bệnh nhân và thời gian dài hơn nữa.

\section{TÀI LIẸU THAM KHẢO}

1. Acastello E, Majluf $R$, Garrido $P$, et al. (2003). "Sternal Cleft: A Surgical Opportunity". J Pediatr
Surg, 38:178-183.

2. Alshomer $\mathbf{F}$, Aldaghri $\mathbf{F}$, Alohaideb $\mathbf{N}$, et al. (2017). "Reconstruction of Congenital Sternal Clefts: Surgical Experience and Literature Review". Plast Reconstr Surg Glob Open,5: e1567.

3. Dogan R, Uysal S, Kumbasar U, et al. (2019). "Surgical repair of a sternal cleft malformation". Turkish Journal of Thoracic and Cardiovascular Surgery, 27(4):597-600.

4. Torre M, Rapuzzi G, Carlucci M, et al. (2012). "Phenotypic spectrum and management of sternal cleft: literature review and presentation of a new series". Eur J Cardiothorac Surg, 41:4-9.

5. Fouilloux V, Bertin F, Peltier E, et al. (2019). "First Sternal Cleft Repair Using a Porous Alumina Ceramic Prosthesis in a 9-Year-Old Child". Eur J Pediatr Surg Rep,7: e20-e23.

6. Ramdial S, Pillay D, Madaree A. (2016). "Primary Closure of A Sternal Cleft in A Neonate". World J Plast Surg,5(3):308-312.

7. Semlacher RA, Nuri MAK. (2019). "Successful management of absent sternum in an infant using porcine acellular dermal matrix". Arch Plast Surg, 46: 470-474.

8. Yamanaka $K$, Higuma $T$, Wantanabe $K$, et al. (2012). "Congenital sternal cleft". Journal of Pediatric Surgery, 47, 2143-2145.

9. Raff GW, Hirose S. (2017). "Surgery for chest wall deformities", (c) Springer International Publishing Switzerland, 71-81.

\title{
KIẾN THỨC, THÁI Độ VÀ THỰC HÀNH PHÒNG CHỐNG DICH COVID-19 CỦA NGƯờI DÂN TRÊN 18 TUỔI TẠI TİNH ĐẮK LẮK NĂM 2021
}

\section{TÓM TẮT}

Bằng phương pháp nghiên cứu mô tả cắt ngang với việc thu thập dữ liệu trực tuyến và đăng liên kết khảo sát trên nhóm Google form. Chúng tôi đã thực hiên khảo sát 1.154 người dân từ 18 tuổi trở lên về kiển thức, thái độ, thực hành phòng, chống dịch COVID-19 tai tỉnh Đắk Lắk. Mẫu nghiên cứu có $44,5 \%$ nam giới và $55,5 \%$ là nữ giới. Độ tuổi trung bình là $35,9 \pm 11,9$ tuổi. Dân tộc Kinh chiếm 49,8\%, Ê Đê chiếm $39,5 \%$ và $M^{\prime}$ Nông là 10,7\%. Có $77,2 \%$ người không theo tôn giáo nào. Trình độ học vấn chủ yếu từ cấp 2 trở lên. $41,9 \%$ có nghề nghiệp là nông dân. $74,5 \%$ có kinh tế hộ gia đình ở mức trung bình. Có $83,9 \%$ ở khu vực nông thôn và $16,1 \%$ ở khu vực thành thị. Có $7,2 \%$ người tham gia nghiên cứu đã mẳc

${ }^{1}$ Bệnh viện Đa khoa Vùng Tây Nguyên.

2Trung Tâm Y tế Thành phố Buôn Ma Thuột

${ }^{3}$ Sở Y tế tỉnh Đắk Lăkk.

Chịu trách nhiệm chính: Nguyễn Ngọc Như Khuê

Email: nhukhuenguyen@gmail.com

Ngày nhận bài: 25.10.2021

Ngày phản biên khoa hoc: 22.12.2021

Ngày duyệt bài: 29.12.2021
COVID-19 và $4,1 \%$ trong gia đình đã hoăc đang có người bị mắc COVID-19. Có 99,39\% người tham gia nghiên cứu đã được nghe nói về dịch COVID-19. Kênh tiếp nhận thông tin về dịch COVID-19: 87,8\% từ báo chí, truyền hình; $86,3 \%$ từ internet, mạng xã hội; $84,4 \%$ từ cán bộ y tế và loa phát thanh $82,8 \%$. Điểm trung bình chung của kiến thức là 29,16 $\pm 5,5 / 45$ điểm. Điểm trung bình chung của thái độ là 14,95 \pm $1,6 / 16$ điểm. Điểm trung bình chung của thực hành là $26,7 \pm 4,5 / 32$ điểm. Không có sự khác biệt giữa nam và nữ $(p=0,96)$, giữa các độ tuổi $(p=0,29)$ về kiến thức chung, thái độ chung và thực hành chung về phòng, chống dich COVID-19. Có sự khác biêt kiến thức chung, thái độ chung và thực hành chung về phòng, chống dịch COVID-19 với dân tộc $(p<0,01)$, tôn giáo $(p<0,01)$, trình độ học vấn $(p<0,01)$, nghế nghiệp $(p<0,01)$, kinh tế hộ gia đình $(p<0,01)$ và khu vực sinh sống $(p<0,01)$. Nguồn thông tin về dịch COVID-19 từ báo chí, truyền hình, internet, mang xã hội, hàng xóm và người thân có liên quan đến kiến thức chung, thái độ chung và thực hành chung phòng, chống dịch COVID-19 $(p=0,000)$. Nguồn thông tin về dịch COVID-19 từ loa phát thanh chỉ có liên quan đến kiến thức chung $(p=0,001)$. Có mối tương quan thuận giữa kiến thức chung với thái độ chung $(r=0,490$, $\mathrm{N}=1.154$ và $\mathrm{p}=0,000)$ và thực hành chung ( $r=0,601$, 
$\mathrm{N}=1.154, \mathrm{p}=0,000)$ về phòng chống dịch COVID-19. Có mối tương quan thuân giữa thái đô chung với thực hành chung $(r=0,545, n=1.154, p=0,000)$ về phòng chônng dich COVID-19.

Tư khóa: Kiến thức, Thái độ, Thực hành, COVID19, Đắk Lắk, Liên quan.

\section{SUMMARY \\ KNOWLEDGE, ATTITUDE AND PRACTICE TO PREVENT COVID-19 OF PEOPLE OVER 18 YEARS IN DAK LAK PROVINCE 2021}

By cross-sectional descriptive research method with online data collection and survey link posting on Google form group. We conducted a survey of 1,154 people over 18 years about their knowledge, attitudes, and practices in COVID-19 prevention in Dak Lak province.The study sample consisted of $44.5 \%$ men and $55.5 \%$ women. The mean age was $35.9 \pm 11.9$ years old. The Kinh account for $49.8 \%$, the Ede $39.5 \%$ and the M'Nong $10.7 \%$. There were $77.2 \%$ people who do not follow any religion. Education level was mainly from high school and above. $41.9 \%$ had an occupation as a farmer. $74.5 \%$ had an average household economy. There were $83.9 \%$ in rural areas and $16.1 \%$ in urban areas. $7.2 \%$ of study participants had COVID-19 and $4.1 \%$ had or had a family member with COVID-19. There was $99.39 \%$ of the study participants had heard about the COVID-19 epidemic. Channel to receive information about the COVID-19 epidemic: $87.8 \%$ from newspapers and television; $86.3 \%$ from internet, social networks; $84.4 \%$ from health workers and loudspeakers $82.8 \%$. The average score of knowledge was $29.16 \pm 5.5 / 45$ points. The overall mean score of attitude was $14.95 \pm 1.6 / 16$ points. The overall average score of practice was 26.7 $\pm 4.5 / 32$ points. There was no difference between men and women $(p=0.96)$ and between ages $(p=$ 0.29 ) in terms of common knowledge, common attitudes and practices on COVID-19 prevention. There was a difference in common knowledge, common attitude and common practice on COVID-19 prevention and control with ethnicity $(p<0.01)$, religion $(p<0.01)$, education level $(p) .<0.01)$, occupation $(p<0.01)$, household economy $(p<0.01)$ and living area $(p<0.01)$. Sources of information about the COVID-19 epidemic from the press, television, the internet, social networks, neighbors and relatives related to common knowledge, common attitudes and common practices in COVID-19 prevention and control $(p=0.0000)$. The source of information about the COVID-19 epidemic from loudspeakers was only related to general knowledge $(p=0.001)$. There is a positive correlation between common knowledge and common attitude $(r=0.490, N=1,154$ and $p=0,000)$ and common practice $(r=0,601, N=1,154, p=0,000)$ on COVID-19 prevention. There is a positive correlation between common attitude and common practice $(r=0,545, n=1,154$, $\mathrm{p}=0,000)$ on COVID-19 prevention.

Keywords: Knowledge, Attitude, Practice, COVID19, Dak Lak, Correlation.

\section{I. ĐĂT VẤN ĐỀ}

Bệnh COVID-19 là bệnh truyền nhiễm cấp tính thuộc nhóm A do vi rút SARS-CoV-2 gây ra. Bệnh COVID-19 lây truyền từ người sang người qua đường hô hấp. Thời gian ủ bệnh trong khoảng 14 ngày. Phần lớn (hơn 60\%) người nhiễm vi rút SARS-CoV-2 không có biểu hiên lâm sàng. Đối với người mắc bệnh có triệu chứng thì biểu hiện lâm sàng rất đa dạng có thể từ nhẹ đến nặng như: sốt, ho, đau họng, người mêtt mỏi, đau người, giảm hoặc mất vi giác hoặc khứu giác, khó thở, có thể có viêm phổi nặng, suy hô hấp cấp và tử vong, đặc biệt ở những người có bệnh lý nền, người có bênh lý man tính, người cao tuổi. Đến nay, bênh đã có vắc xin phòng bệnh nhưng chưa có thuốc điều trị đặc hiệu [1].

Tính đến ngày 06/12/2021, Đắk Lắk đã ghi nhận 8.524 trường hợp mắc tại 15/15 huyện, thị xã, thành phố; 44 trường hợp tử vong; 6.330 trường hợp hoàn thành điều trị và xuất viện; hiện còn điều trị 2.150 trường hợp[2]. Diễn biến dich COVID-19 ở tỉnh phức tap và việc tổ chức các biện pháp phòng chống dịch để giảm số mắc và số tử vong vẫn là một thách thức lớn đối với tỉnh. Đo đó, việc đánh giá kiến thức, thái độ và thực hành phòng, chống dịch COVID-19 của người dân trên 18 tuổi là rất cần thiết nhằm đóng góp bằng chứng cho truyền thông giáo dục sức khỏe để nâng cao hiệu quả công tác phòng, chống dịch trên đia bàn tỉnh. Trên Thế giới và Việt nam đã có nhiều nghiên cứu về vấn đề này, nhưng trên địa bàn tỉnh Đắk Lắk chưa có một nghiên cứu nào về kiến thức, thái độ và thực hành phòng, chống dịch COVID-19 của người dân trên 18 tuổi nên chúng tôi đã tiến hành thực hiện nghiên cứu này với mục tiêu:

- Mô tả kiến thức, thái đồ và thực hành phòng, chống dịch COVID-19 của người dân trên 18 tuối.

- Xác định nhóm đôi tượng chưa có đủ kiên thức, thái độ, thực hành phòng, chông dịch COVID-19 để tác động truyền thông giáo dục sức khỏe.

\section{II. ĐỐI TƯợNG VÀ PHƯƠNG PHÁP NGHIÊN CỨU}

2.1. Đối tượng nghiên cứu. Người dân trên 18 tuổi có địa chì thường trú trên địa bàn tỉnh Đắk Lắk.

2.2. Địa điểm và thời gian nghiên cứu

- Đia điểm: tỉnh Đắk Lắk

- Thời gian: Tháng $9-10 / 2021$

2.3. Thiết kế nghiên cứu. Nghiên cứu mô tả cắt ngang. Chúng tôi quyết định thu thập dữ liệu trực tuyến và đăng liên kết khảo sát trên nhóm Google form. Bài đăng trực tuyến này bao gồm một đoạn giới thiệu ngắn về mục tiêu 
nghiên cứu của chúng tôi và tuyên bố về tính bảo mật. Những người dân trên 18 tuổi sống ở tỉnh và chấp nhận tham gia vào nghiên cứu đã được cán bộ y tế chuyên trách về COVID-19 ở các Trạm Y tế xã phỏng vấn để điền vào bảng câu hỏi thông qua việc nhấp vào liên kêt.

\subsection{Phương pháp nghiên cứu}

2.4.1. Cỡ mâuu. Áp dụng công thức ước lượng một tỷ lệ.

$$
\mathbf{n}=\frac{\mathbf{Z}_{(1-\alpha / 2)}^{2} \mathbf{p}(1-\mathbf{p})}{\boldsymbol{d}^{2}} * \mathrm{DE}
$$

- n: Cõ̃ mẫu nghiên cứu tối thiểu

- a: xác suất sai lầm loại $I(a=0,05)$.

- Z: trị số từ phân phối chuẩn $\left(Z_{0,95}=1,96\right.$ với khoảng tin cậy $95 \%)$.

- p: Tỷ lệ người dân trên 18 tuổi có thực hành tốt về phòng, chống dịch COVID-19. Ớ đây, chúng tôi lấy giá trị $p=0,5$.

- $d$ : Sai số cho phép $(d=0,05)$.

- DE: Hệ số hiệu ứng thiết kế (Chọn DE = 3). Việc chọn hệ số hiệu ứng thiết kế sẽ làm cõ̃ mẫu tăng lên, nhưng bù lại làm giảm sai chệch do lây cõ mẫu theo trạm y tế xã, phường, thị trấn.

Cỡ mẫu ước tính cần cho nghiên cứu là $n=$ 1.152 mẫu. Chúng tôi dự kiến sẽ thu thập 1.160 mẫu cho nghiên cứu này. Thực tế đã chúng tôi đã phỏng vấn được 1.154 người dân trên 18 tuổi tham gia vào nghiên cứu này.

\subsubsection{Kỹ thuật chọn mẫu}

Chơn mấu thuân tiện. Toàn tỉnh có 184 Trạm Y tế xã, phường, thị trấn tham gia vào nghiên cứu. Mỗi Trạm y tế sẽ thu thập từ $6-7$ phiếu phỏng vấn một cách ngẫu nhiển. Thực tế đã chúng tôi đã phỏng vấn được 1.154 người dân trên 18 tuổi tham gia vào nghiên cứu này.

Mỗi Trạm y tế có 1 cán bộ y tế chuyên trách về COVID-19 sẽ trực tiếp phỏng vấn ngẫu nhiên người dân trên 18 tuổi để điền vào bảng câu hỏi thông qua việc nhấp vào liên kết.

Thu thập số liệu Phỏng vấn trực tiếp bằng bộ câu hỏi được thiết kế dựa trền hướng dẫn chuyên môn của Bộ $Y$ tế và nghiên cứu của chúng tôi đánh giá kiến thức, thái độ và thực hành của người dân trên 18 tuổi về phòng, chống dịch COVID-19.

Bộ câu hỏi được thiết kế và phỏng vấn thử cho 10 người dân trên 18 tuổi một cách ngẫu nhiên để hiệu chỉnh cho phù hợp. Bộ câu hỏi gồm 4 phần: Phần 1: Thông tin chung có 13 câu bao gồm các câu hỏi về đặc điểm dân số - xã hội của đối tượng nghiên cứu như tuổi, giới, dân tộ̣c, tôn giáo, trình độ học vấn, nghề nghiệp, tình trạng kinh kế gia đình, nơi sinh sống, vấn đề mắc COVID-19; Phần 2: đánh giá kiến thức gồm có 16 câu hỏi gồm những nội dung đã được truyền thông giáo dục sức khỏe về phòng chống dịch COVID-19: thông tin về dịch, nguyên nhân gây ra bệnh, sự nguy hiểm của bệnh, các triệu chứng, đường lây truyền, thông đieêp " $5 K$ ", các biện pháp phòng bệnh; Phần 3: đánh giá thái độ gồm có 8 câu hỏi với các nội dung: lo sợ về dịch bệnh COVID-19, đeo khẩu trang, rửa tay, các biện pháp phòng chống dịch và phần 4: đánh giá thực hành gồm có 16 câu hỏi với các nội dung: vệ sinh cá nhân, đeo khẩu trang, rửa tay, theo dối nhiệt độ cơ thể, hạn chế đến đám đông.

2.4.5. Phương pháp phân tích số liệu. Bộ câu hỏi gồm 4 phần: Thông tin chung bao gồm các câu hỏi về đặc điểm dân số - xã hội của đối tượng nghiên cứu như tuổi, giới, dân tộc, tôn giáo, trình độ học vấn, nghề nghiệp, tình trạng kinh kế gia đình, nơi sinh sống, vấn đề mắc COVID-19; Phần 2: đánh giá kiến thức gồm có 16 câu hỏi về kiến thức phòng chống dịch COVID-19 với nội dung trả lời: có hoặc không với tổng điểm 45 điểm chia ra 3 mức: $\geq 80 \%$ điểm tương ứng với $\geq 36$ điểm, 60 - 79\% điểm tương ứng với $27-35$ điểm và $<60 \%$ điểm tương ứng với $\leq 26$ điểm. Phần 3: đánh giá thái độ gồm có 8 câu hỏi về thái độ phòng chống dịch COVID-19 sử dụng thang đo Likert 3 mức độ từ cần thiết, bình thường đến không cân thiết với tổng điểm 16 điểm chia ra 3 mức: $\geq 80 \%$ điểm tương ứng với $\geq 13$ điểm, 60 - 79\% điểm tương ứng với 10 - 12 điểm và $<60 \%$ điểm tương ứng với $\leq 9$ điểm. Phần 4: đánh giá thực hành gồm có 16 câu hỏi về thực hành phòng chống dịch COVID19 sử dụng thang đo Likert 3 mức độ từ cần thiết, bình thường đến không cần thiết với tổng điểm là 32 chia ra 3 mức: $\geq 80 \%$ điểm tương ứng với $\geq 26$ điểm, 60 - 79\% điểm tương ứng với 20 - 25 điểm và $<60 \%$ điểm tương ứng với $\leq 19$ điểm $[3,4,5]$.

Số liệu được nhập và xử lý bằng phần mềm SPSS 20 và Microsoft Excel 2010.

\section{KẾT QUẢ NGHIÊN CứU}

3.1. Đặc điểm của mẫu nghiên cứu

Bảng 1. Đặc điểm của mẩu nghiên cứu

\begin{tabular}{|c|c|c|}
\hline Đặc điểm & $\begin{array}{c}\text { Tân số } \\
(\mathrm{N}=1.154)\end{array}$ & $\begin{array}{l}\text { Týlệ } \\
(\%)\end{array}$ \\
\hline Giới tính: Nam & 514 & 44,5 \\
\hline Nũ̃ & 640 & 55,5 \\
\hline Tuối: Từ 18-29 tuối & 377 & 32,7 \\
\hline Từ 30-39 tuối & 439 & 38,0 \\
\hline Từ 40-49 tuối & 164 & 14,2 \\
\hline Tữ 50-59 tuối & 121 & 10,5 \\
\hline Từ 60 tuối trở lên & 53 & 4,6 \\
\hline
\end{tabular}




\begin{tabular}{|c|c|c|}
\hline $\begin{array}{r}\text { Độ tuối trung bìn } \\
\text { (nhỏ nhất là } 18 \text { và I }\end{array}$ & $\begin{array}{l}\text {, } \\
\text { hất là }\end{array}$ & \\
\hline Dân tộc: Kinh & 575 & 49,8 \\
\hline E Đê & 456 & 39,5 \\
\hline M' Nông & 123 & 10,7 \\
\hline Tôn giáo & & \\
\hline Thiên chúa giáo & 67 & 5,8 \\
\hline Tin lành & 147 & 12,7 \\
\hline Phật giáo & 36 & 3,1 \\
\hline Không & 891 & 77,2 \\
\hline Khác & 13 & 1,1 \\
\hline Trình độ học vấn & & \\
\hline Không biết đọc, biết viết & 15 & 1,3 \\
\hline Cấp 1 & 89 & 7,7 \\
\hline Cấp 2 & 342 & 29,6 \\
\hline Cấp 3 & 321 & 27,8 \\
\hline $\begin{array}{l}\text { Trung cấp, cao đắng, } \\
\text { đai hoc }\end{array}$ & 387 & 33,5 \\
\hline Nghề nghiệp & & \\
\hline Nông dân & 484 & 41,9 \\
\hline Công nhân & 161 & 14,0 \\
\hline Sinh viên & 38 & 3,3 \\
\hline $\begin{array}{l}\text { Cán bộ, công chức, viên } \\
\text { chức }\end{array}$ & 267 & 23,1 \\
\hline Lao động tự do & 140 & 12,1 \\
\hline Khác & 64 & 5,5 \\
\hline Kinh tế hộ gia đình & & \\
\hline Nghèo, cận nghèo & 179 & 15,5 \\
\hline Trung bình & 860 & 74,5 \\
\hline Trên trung bình & 115 & 10,0 \\
\hline Khu vực sinh sống & & \\
\hline Thành thi & 186 & 16,1 \\
\hline Nông thôn & 968 & 83,9 \\
\hline
\end{tabular}

Theo bảng 1 cho thấy có $44,5 \%$ là nam giới và $55,5 \%$ là nữ giới tham gia vào nghiên cứu này. Độ tuổi trung bình là 35,9 $\pm 11,9$ (nhỏ nhất là 18 và lớn nhất là 92 tuổi), trong đó nhóm tuổi từ 30-39 tuổi chiếm cao nhất là 38\%. Phân bô theo dân tộc thì dân tộc Kinh chiếm 49,8\%, Ê Đê chiếm $39,5 \%$ và $M^{\prime}$ Nông là $10,7 \%$. Có $77,2 \%$ người tham gia nghiên cứu không theo tôn giáo nào. Trình độ học vấn chủ yếu từ cấp 2 trở lên, cao nhất ở trình độ trung cấp, cao đẳng, đại học là $33,5 \%$. Nghề nghiệp của nhóm tham gia nghiên cứu chủ yếu là nông dân chiếm $41,9 \%$. Có 74,5\% người tham gia nghiên cứu có kinh tế hộ gia đình ở mức trung bình. Có 83,9\% người tham gia nghiên cứu ở khu vực nông thôn và $16,1 \%$ ở khu vực thành thị.

Bảng 2. Một số đặc điểm có liên quan đến tình trạng mắc COVID-19

\begin{tabular}{|c|c|c|}
\hline Đặc điểm & $\begin{array}{c}\text { Tần số } \\
\text { (N=1.154) }\end{array}$ & $\begin{array}{c}\text { Tỷ lệ } \\
\mathbf{( \% )}\end{array}$ \\
\hline Tình trạng đã măc COVID-19 \\
\hline Có & 83 & 7,2 \\
\hline Không & 1.071 & 92,8 \\
\hline \multicolumn{2}{|c}{} \\
\hline
\end{tabular}

Gia đình đã hoă̆c đang có người bị mắc COVID-19

\begin{tabular}{|c|c|c|}
\hline Có & 47 & 4,1 \\
\hline Không & 1.107 & 95,9 \\
\hline
\end{tabular}

Sống gân nhà người đã mắc COVID-19

\begin{tabular}{|c|c|c|}
\hline Có & 106 & 9,2 \\
\hline Không & 1.048 & 90,8 \\
\hline
\end{tabular}

Từng đĩ cách ly vì nghi ngờ nhiềm COVID-19

\begin{tabular}{|l|l|l|}
\hline Đã từng cách ly tập trung & 81 & 7,0
\end{tabular}

\begin{tabular}{|l|l|l|}
\hline Đã từng cách ly tại nhà & 161 & 14,0 \\
\hline
\end{tabular}

\begin{tabular}{l|l|l}
\hline Chưa khi nào & 912 & 79,0
\end{tabular}

Theo bảng 2 cho thấy có $7,2 \%$ người tham gia nghiên cứu đã mắc COVID-19 và $4,1 \%$ trong gia đình đã hoặc đang có người bị mắc COVID19. Có $9,2 \%$ người tham gia nghiên cứu sống gần nhà người đã mắc COVID-19. Có 7\% người tham gia nghiên cứu đã từng cách ly tập trung và $14 \%$ đã từng cách ly tại nhà.

Bảng 3. Thông tîn và kênh tiếp nhận thông tîn về dịch COVID -19

\begin{tabular}{|c|c|c|}
\hline $\begin{array}{c}\text { Thông tin về dịch } \\
\text { COvID -19 }\end{array}$ & $\begin{array}{c}\text { Tần số } \\
\text { (N=1.154) }\end{array}$ & $\begin{array}{c}\text { Tỷ lệ } \\
\mathbf{( \% )}\end{array}$ \\
\hline \multicolumn{2}{|c|}{ Nghe nói về dịch COVID-199 } \\
\hline Có & 1.147 & 99,39 \\
\hline Không & 7 & 0,61 \\
\hline Kênh tiếp nhận thông tin về dịch COVID -19 \\
\hline Báo chí, truyền hình & 1.001 & 87,8 \\
\hline Internet, mạng xã hội & 990 & 86,3 \\
\hline Cán bộ y tế & 968 & 84,4 \\
\hline Loa phát thanh & 950 & 82,8 \\
\hline Hàng xóm, người thân & 765 & 66,7 \\
\hline Khác & 107 & 9,3 \\
\hline
\end{tabular}

Theo bảng 3 cho thây có $99,39 \%$ người tham gia nghiên cứu đã được nghe nói về dịch COVID -19. Kênh tiếp nhận thông tin về dịch COVID-19 chủ yếu từ các nguồn: $87,8 \%$ từ báo chí, truyên hình; 86,3\% từ internet, mạng xã hội; 84,4\% từ cán bộ y tế và loa phát thanh $82,8 \%$.

3.2. Kiến thức, thái độ và thực hành phòng chống dịch COVID-19

Bảng 4. Điếm trung binh chung của kiến thức, thái độ và thực hành phòng chống dich COVID-19

\begin{tabular}{|c|c|c|c|}
\hline $\begin{array}{c}\text { Noội } \\
\text { dung }\end{array}$ & $\begin{array}{c}\text { Tống } \\
\text { điểm }\end{array}$ & \multicolumn{2}{|c|}{ Điểm trung bình } \\
\hline $\begin{array}{c}\text { Kiến } \\
\text { thức }\end{array}$ & 45 & $\begin{array}{c}29,16 \\
\pm 5,5\end{array}$ & $\begin{array}{c}\text { (nhỏ nhất là 1 và } \\
\text { lớn nhất là 42) }\end{array}$ \\
\hline $\begin{array}{c}\text { Thái } \\
\text { độ }\end{array}$ & 16 & $\begin{array}{c}14,95 \\
\pm 1,6\end{array}$ & $\begin{array}{c}\text { (nhỏ nhất là 6 và } \\
\text { lớn nhất là 16) }\end{array}$ \\
\hline $\begin{array}{c}\text { Thực } \\
\text { hành }\end{array}$ & 32 & $\begin{array}{c}26,7 \pm \\
4,5\end{array}$ & $\begin{array}{c}\text { (nhỏ nhất là 2 và } \\
\text { lớn nhất là 32) }\end{array}$ \\
\hline
\end{tabular}

Bảng 4 cho thấy điểm trung bình chung của kiến thức là $29,16 \pm 5,5$ trên tổng số 45 điểm, điểm trung bình chung của thái độ là 14,95 \pm 
1,6 trên tổng số điểm là 16 và điểm trung bình chung của thực hành là $26,7 \pm 4,5$ trên tổng số điểm là 32.

Bảng 5. Kiên thức chung phòng chống dịch COVID-19

Kiến thức chung

\begin{tabular}{c|c}
$\begin{array}{c}\text { Số lượng } \\
(\mathbf{N}=1.154)\end{array}$ & $\begin{array}{c}\text { Tỷ lệ } \\
(\%)\end{array}$
\end{tabular}

\begin{tabular}{|c|c|c|}
\hline$\geq 80 \%$ & 75 & 6,5 \\
\hline $60-79 \%$ & 793 & 68,7 \\
\hline$<60 \%$ & 286 & 24,8 \\
\hline
\end{tabular}

Bảng 5 cho thấy chỉ có $6,5 \%$ người tham gia nghiên cứu có kiến thức tốt và $68,7 \%$ người tham gia nghiên cứu có kiến thức trung bình khá về phòng chống dịch COVID -19.

Bảng 6: Kêt quả trả lời đúng về kiến thức phòng, chống dịch COVID-19

\begin{tabular}{|c|c|c|}
\hline Kiến thức & $\begin{array}{c}\text { Tân số } \\
(\mathbf{N}=1.154)\end{array}$ & $\begin{array}{l}\text { Tỷ lê̂ } \\
(\%)\end{array}$ \\
\hline Nghe nói về bệnh COVID-19 & 1.147 & 99,4 \\
\hline Bệnh COVID-19 là 1 bệnh truyền nhiềm & 1.122 & 97,2 \\
\hline Vi rút là nguyên nhân gây ra bệnh COVID-19 & 1.028 & 89,1 \\
\hline Thời gian ủ bệnh của bệnh COVID-19 từ 3-14 ngày & 880 & 76,3 \\
\hline Điều tri triêu chứng đối với bênh COVID-19 & 727 & 63,0 \\
\hline Bệnh COVID-19 nguy hiếm hơn ở lứa tuối trên 50 tuổi & 911 & 78,9 \\
\hline Các triêu chứng của bênh COVID-19 & 93 & 8,1 \\
\hline Bệnh COVID-19 có thể lây qua đường nào & 153 & 13,3 \\
\hline Hạn chế tiếp xúc với người bị nghi ngờ nhiếm COVID-19 & 1.125 & 97,5 \\
\hline Bệnh COVID-19 đang gia tăng ở Đắk Lắk & 946 & 82,0 \\
\hline Nắm vững Thông điệp " $5 \mathrm{~K}$ " của Bộ Y tế & 1.052 & 91,2 \\
\hline Rửa tay bằng nước và xà phòng có thể loại bỏ nguyên nhân gây bệnh COVID-19 & 995 & 86,2 \\
\hline $\begin{array}{l}\text { Người mắc COVID-19 không thể truyền bệnh cho người khác khi chưa có } \\
\text { biểu hiện bệnh (sốt, ho, khó thở...) }\end{array}$ & 647 & 56,1 \\
\hline $\begin{array}{c}\text { Bệnh COVID-19 nguy hiếm hớn và có thế tử vong ở phụ nữ mang thai, } \\
\text { người lớn tuối, người có hệ miễn dịch suy yếu, bệnh mãn tính }\end{array}$ & 622 & 53,9 \\
\hline Những biện pháp giúp phòng ngừa mắc COVID-19 & 643 & 55,7 \\
\hline
\end{tabular}

Theo bảng 6 cho thẫy người tham gia nghiên cứu trả lời đúng về các triệu chứng của bệnh COVID-19 chỉ có 8,1\%, bệnh COVID-19 lây truyền qua đường nào là 13,3\%, bệnh COVID-19 nguy hiểm hơn và có thể tử vong là $53,9 \%$, người mắc COVID-19 lây truyền bệnh là $56,1 \%$ và những biện pháp giúp phòng ngừa mắc COVID-19 là $55,7 \%$.

Bảng 7. Phân tích mốt số nội dung chính của kiên thức phòng chống dịch COVID-19

\begin{tabular}{|c|c|c|c|}
\hline Nội dung chính của kiến thức & $\mathbf{2} \mathbf{8 0} \%$ & $\mathbf{6 0 - 7 9 \%}$ & $<\mathbf{6 0 \%}$ \\
\hline Các triệu chứng COVID-19 & $35(3 \%)$ & $3(0,3 \%)$ & $1116(96,7 \%)$ \\
\hline Đường lây COVID-19 & $323(28 \%)$ & $347(30,1 \%)$ & $484(41,9 \%)$ \\
\hline Thực hiện các biện pháp khi nghi nhiếm & $458(39,7 \%)$ & $294(25,5 \%)$ & $402(34,8 \%)$ \\
\hline Độ tuổi nguy hiểm & $622(53,9 \%)$ & $302(26,2 \%)$ & $230(19,9 \%)$ \\
\hline Các biện pháp phòng ngữa COVID-19 & $860(74,5 \%)$ & $203(17,6 \%)$ & $91(7,9 \%)$ \\
\hline
\end{tabular}

Theo bảng 7 cho thấy chỉ có $3 \%$ kiến thức tốt về các triệu chứng, $28 \%$ kiến thức tốt về đường lây và 39,7\% kiến thức tốt thực hiện các biện pháp xử lý khi nghi nhiếm COVID-19. Có 53,9\% kiến thức tốt về độ tuổi nguy hiểm khi mắc bệnh và có $74,5 \%$ kiến thức tốt về các biện pháp phòng ngừa COVID-19.

Bảng 8. Thái độ chung phòng chống dịch COVID-19

\begin{tabular}{|c|c|c|}
\hline Thái độ chung & Số lượng (n=1.154) & Tỷ lệ (\%) \\
\hline$\geq 80 \%$ & 1.046 & 90,6 \\
\hline $60-79 \%$ & 83 & 7,2 \\
\hline$<60 \%$ & 25 & 2,2 \\
\hline
\end{tabular}

Theo bảng 8 cho thây có $90,6 \%$ người tham gia nghiên cứu có thái độ chung tích cực phòng chống dịch COVID-19.

Bảng 9. Thái độ tích cực phòng, chống dịch COVID-19

Thái độ tích cực về phòng, chống dịch COVID-19 Sợ dịch bênh COVID-19

Khuyến cáo giải pháp phòng ngừa cho cá nhân

Tân số ( $\mathbf{N}=1.154)$

686

1.118

ỷ lệ \%

96,9 


\begin{tabular}{|c|c|c|}
\hline Khuyến cáo giải pháp đảm bảo vệ sinh nhà cửa & 1.076 & 93,2 \\
\hline Khuyến cáo giải pháp phòng ngưaa cho cộng đồng & 1.117 & 96,8 \\
\hline Khuyến cáo việc đeo khẩu trang đúng cách & 1132 & 98,1 \\
\hline Khuyến cáo việc rửa tay đúng cách & 1.105 & 95,8 \\
\hline Tỉnh sẽ khống chế được dịch COVID-19 & 1.003 & 86,9 \\
\hline Tin tưởng vào các biện pháp chống dịch & 1.059 & 91,8 \\
\hline
\end{tabular}

Bảng 9 cho thấy, người tham gia nghiên cứu có thái độ tích cực phòng, chống dịch COVID-19. Có 59,4\% người tham gia nghiên cứu có thái độ lo sợ dịch bệnh COVID-19.

Bảng 10. Thực hành chung phòng chống dịch COVID -19

\begin{tabular}{|c|c|c|}
\hline Thực hành chung & Số lượng (n=1.154) & Tỷ lệ (\%) \\
\hline$\geq 80 \%$ & 803 & 69,5 \\
\hline $60-79 \%$ & 265 & 23,0 \\
\hline$<60 \%$ & 86 & 7,5 \\
\hline
\end{tabular}

Theo bảng 10 cho thấy có $69,5 \%$ người tham gia nghiên cứu có thực hành đúng phòng chống dịch COVID-19.

Bảng 11. Thực hành tích cực phòng, chống dịch COVID-19

\begin{tabular}{|c|c|c|}
\hline Thực hành tích cực về COVID-19 & Tân số $(\mathrm{N}=1.154)$ & Tỷ lệ \% \\
\hline Không ra khỏi nhà khi không cần thiết & 1.043 & 90,4 \\
\hline Tránh kỳ nghỉ không cân thiết & 1.045 & 90,6 \\
\hline Tránh đi mua và ăn các thức ăn chế biến sằn bên ngoài & 864 & 74,9 \\
\hline Tránh bắt tay, ôm, hôn người khác & 1.059 & 91,8 \\
\hline Tránh đi bằng các phương tiện giao thông công cộng & 1.001 & 86,7 \\
\hline Hạn chế đi làm tại cơ quan & 610 & 52,9 \\
\hline Chú ý vệ sinh cá nhân hơn bình thường & 1.088 & 94,3 \\
\hline Không có thói quen khạc nhố bừa bãi & 873 & 75,6 \\
\hline Sử dụng chất khử trùng nhà cửa và bề mặt & 1.017 & 88,1 \\
\hline Sử dụng thảo dược và y học cố truyền & 405 & 35,1 \\
\hline Uống bố sung Vitamin C & 842 & 73,0 \\
\hline Tâp thế dục rèn luyên sức khỏe & 850 & 73,7 \\
\hline Sằn sàng tiểm vắc xin khi đến lượt & 1.118 & 96,9 \\
\hline Vệ sinh tay & 876 & 75,9 \\
\hline Về theo dõi nhiêt đô & 900 & 78,0 \\
\hline Về đeo khẩu trang & 1.146 & 99,3 \\
\hline
\end{tabular}

Bảng 11 cho thấy, người tham gia nghiên cứu có thực hành tích cực về phòng, chống dịch COVID19. Có $35,1 \%$ có thực hành tích cực về sử dụng thảo dược và y học cổ truyền, $52,9 \%$ việc hạn chế đi làm tại cơ quan, $73 \%$ về uống bổ sung Vitamin C, 73,7\% tập thể dục rèn luyện sức khỏe và $75,9 \%$ có thái độ tích cực về vệ sinh tay.

3.3. Xác định nhóm đối tượng chưa có đủ kiến thức, thái độ, thực hành phòng, chống dịch COVID-19 để tác động truyến thông giáo dục sức khỏe

Bảng 12. Mối liên quan giữa đặc điểm chung và kiến thức chung phòng, chống dịch COVID-19

\begin{tabular}{|c|c|c|c|c|c|}
\hline \multirow{2}{*}{\multicolumn{2}{|c|}{ Đặc điểm chung }} & \multicolumn{4}{|c|}{ Kiến thức chung $(\mathrm{N}=1.154)$} \\
\hline & & \multirow{2}{*}{$\begin{array}{c}\geq \mathbf{8 0} \% \\
34(6,6 \%)\end{array}$} & $60-79 \%$ & \multirow{2}{*}{$\begin{array}{c}<\mathbf{6 0 \%} \\
129(25,1 \%)\end{array}$} & \multirow{3}{*}{$\frac{\mathbf{p}}{0,96}$} \\
\hline Giới & Nam & & $351(68,3 \%)$ & & \\
\hline & Nũ & $41(6,4 \%)$ & $442(69,1 \%)$ & $157(24,5 \%)$ & \\
\hline \multirow{5}{*}{ Nhóm tuối } & 18-29 tuổi & $23(6,1 \%)$ & $247(65,5 \%)$ & $107(28,4 \%)$ & \multirow{5}{*}{0,29} \\
\hline & 30-39 tuổi & $35(8 \%)$ & $301(68,6 \%)$ & $103(23,5 \%)$ & \\
\hline & $40-49$ tuối & $7(4,3 \%)$ & $125(76,2 \%)$ & $32(26,4 \%)$ & \\
\hline & 50-59 tuổi & $5(5 \%)$ & $83(68,6 \%)$ & $12(22,6 \%)$ & \\
\hline & Từ 60 tuối trở lên & $0(0 \%)$ & $37(69,8 \%)$ & $286(24,8 \%)$ & \\
\hline \multirow[t]{3}{*}{ Dân tộc } & Kinh & $42(7,3 \%)$ & $437(76 \%)$ & $96(16,7 \%)$ & \multirow{3}{*}{0,000} \\
\hline & Ê Đê & $30(6,6 \%)$ & $268(58,8 \%)$ & $158(34,6 \%)$ & \\
\hline & M' Nông & $0(0 \%)$ & $88(71,5 \%)$ & $32(26 \%)$ & \\
\hline
\end{tabular}


TẠP CHÍ Y HỌC VIẸT NAM TẬP 510 - THÁNG 1 - SÓ 1 - 2022

\begin{tabular}{|c|c|c|c|c|c|}
\hline Tôn giáo & Có & $22(8,4 \%)$ & $146(55,5 \%)$ & $95(36,1 \%)$ & \multirow{2}{*}{0,000} \\
\hline & Không & $53(5,9 \%)$ & $647(72,6 \%)$ & $191(21,4 \%)$ & \\
\hline \multirow{5}{*}{ Trình độ học vấn } & Không biết đọc, viết & $1(6,7 \%)$ & $2(13,3 \%)$ & $12(80 \%)$ & \multirow{5}{*}{0,000} \\
\hline & Cấp 1 & $2(2,2 \%)$ & $46(51,7 \%)$ & $41(46,1 \%)$ & \\
\hline & Cấp 2 & $16(4,7 \%)$ & $205(59,9 \%)$ & $121(35,4 \%)$ & \\
\hline & Cấp 3 & $17(5,3 \%)$ & $222(69,2 \%)$ & $82(25,5 \%)$ & \\
\hline & $\mathrm{TC}, \mathrm{CD}, \mathrm{DH}, \mathrm{S} \boxminus \mathrm{H}$ & $39(10,1 \%)$ & $318(82,2 \%)$ & $30(7,8 \%$ & \\
\hline \multirow{6}{*}{ Nghề nghiệp } & Nông dân & $21(4,3 \%)$ & $308(63,6 \%)$ & $155(32 \%)$ & \multirow{6}{*}{0,000} \\
\hline & Công nhân & $11(6,8 \%)$ & $86(53,4 \%)$ & $64(39,8 \%)$ & \\
\hline & Sinh viên & $1(2,6 \%)$ & $31(81,6 \%)$ & $6(15,8 \%)$ & \\
\hline & CBVC & $28(10,5 \%)$ & $218(81,6 \%)$ & $21(7,9 \%)$ & \\
\hline & Lao đông tư do & $9(6,4 \%)$ & $103(73,6 \%)$ & $28(20 \%)$ & \\
\hline & Khác & $5(7,8 \%)$ & $47(73,4 \%)$ & $12(18,8 \%)$ & \\
\hline \multirow{3}{*}{ Kinh tế hộ gia đình } & Nghèo, cận nghèo & $5(2,8 \%)$ & $82(45,8 \%)$ & $92(51,4 \%)$ & \multirow{3}{*}{0,000} \\
\hline & Trung bình & $63(7,3 \%)$ & $616(71,6 \%)$ & $181(21 \%)$ & \\
\hline & Trên trung bình & $7(6,1 \%)$ & $95(82,6 \%)$ & $13(11,3 \%)$ & \\
\hline \multirow{2}{*}{ Khu vực sinh sống } & Thành thi & $16(8,6 \%)$ & $144(77,4 \%)$ & $26(14 \%)$ & \multirow{2}{*}{0,001} \\
\hline & Nông thôn & $59(6,1 \%)$ & $649(67 \%)$ & $260(26,9 \%)$ & \\
\hline
\end{tabular}

Theo bảng 12 cho thây không có sự khác biệt giữa nam và nữ $(p=0,96)$, giữa các độ tuổi $(p=0,29)$ về kiến thức chung về phòng, chống dịch COVID-19. Có sự khác biệt kiến thức chung về phòng, chống dịch COVID-19 với dân tộc $(p=0,000)$, tôn giáo $(p=0,000)$, trình độ học vấn $(p=0,000)$, nghề nghiệp $(p=0,000)$, kinh tế hộ gia đình $(p=0,000)$ và khu vực sinh sống $(p=0,001)$

Bảng 13. Mối liên quan giữa một số đặc điểm về tình trạng măc COVID-19 với kiên thức chung phòng chống dịch COVID-19

\begin{tabular}{|c|c|c|c|c|c|}
\hline \multirow{2}{*}{\multicolumn{2}{|c|}{ Tình trạng tiếp xúc COVID-19 }} & \multicolumn{4}{|c|}{ Kiến thức chung $(\mathrm{N}=1.154)$} \\
\hline & & $\geq 80 \%$ & $60-79 \%$ & $<60 \%$ & $\mathbf{p}$ \\
\hline \multirow{2}{*}{ Đã mắc COVID-19 } & Có & $10(12 \%)$ & $55(66,3 \%)$ & $18(21,7 \%)$ & \multirow{2}{*}{0,097} \\
\hline & Không & $65(6,1 \%)$ & $738(68,9 \%)$ & $268(25 \%)$ & \\
\hline \multirow{2}{*}{ Gia đình có người mắc } & Có & $5(10,6 \%)$ & $33(70,2 \%)$ & $9(19,1 \%)$ & \multirow{2}{*}{0,38} \\
\hline & Không & $70(6,3 \%)$ & $760(68,7 \%)$ & $277(25 \%)$ & \\
\hline \multirow{2}{*}{ Sống gần nhà người mắc } & Có & $11(10,4 \%)$ & $75(70,8 \%)$ & $20(18,9 \%)$ & \multirow{2}{*}{0,11} \\
\hline & Không & $64(6,1 \%)$ & $718(68,5 \%)$ & $266(25,4 \%)$ & \\
\hline \multirow{3}{*}{ Từng cách ly } & Cách ly tâp trung & $11(13,6 \%)$ & $54(66,7 \%)$ & $16(19,8 \%)$ & \multirow{3}{*}{0,000} \\
\hline & Cách ly tai nhà & $5(3,1 \%)$ & $98(60,9 \%)$ & $58(36 \%)$ & \\
\hline & Không & $59(6,5 \%)$ & $641(70,3 \%)$ & $212(23,2 \%)$ & \\
\hline
\end{tabular}

Theo bảng 13 cho thấy không có mối liên quan với kiến thức chung phòng chống dich COVID-19 giữa những người tham gia nghiên cứu về tình trạng mắc COVID-19 $(\mathrm{p}=0,097)$, gia đình có người mắc COVID-19 $(p=0,38)$, sống gần nhà người mắc COVID-19 $(p=0,11)$. Có mối liên quan giữa những người tham gia nghiên cứu đã từng bị cách ly tập trung, cách ly tại nhà và không bị cách ly với kiến thức chung phòng chống dịch COVID-19 $(p=0,000)$.

Bảng 14. Mối liên quan giữa nguồn thông tín với kiến thức chung, thái độ chung và thực hành chung phòng chống dịch COVID-19 ( $N=1.154)$

\begin{tabular}{|c|c|c|c|c|c|c|}
\hline Nguồn thông tin & $\begin{array}{l}\text { Kiến thức } \\
\text { chung }\end{array}$ & $\mathbf{p}$ & $\begin{array}{l}\text { Thái độ } \\
\text { chung }\end{array}$ & p & $\begin{array}{l}\text { Thực hành } \\
\text { chung }\end{array}$ & p \\
\hline $\begin{array}{r}\text { Báo chí, truyên hình: Có } \\
\text { Không }\end{array}$ & $\begin{array}{l}29,79 \pm 4,7 \\
24,9 \pm 8,0\end{array}$ & 0,000 & $\begin{array}{l}15,1 \pm 1,4 \\
13,9 \pm 2,4\end{array}$ & $\begin{array}{c}0,00 \\
0\end{array}$ & $\begin{array}{c}27,04 \pm 3,99 \\
24,1 \pm 6,25\end{array}$ & $\begin{array}{c}0,00 \\
0\end{array}$ \\
\hline Internet, mạng xã hội: Có & $\begin{array}{l}29,8 \pm 4,7 \\
25,2 \pm 7,6\end{array}$ & 0,000 & $\begin{array}{l}15,05 \pm 1,5 \\
14,34 \pm 2,1\end{array}$ & $\begin{array}{c}0,00 \\
0\end{array}$ & $\frac{27,1 \pm 4,0}{24,2 \pm 5,9}$ & $\begin{array}{c}0,00 \\
0\end{array}$ \\
\hline $\begin{array}{r}\text { Cán bộ y tế: Có } \\
\text { Không }\end{array}$ & $\begin{array}{l}29,7 \pm 5,0 \\
26,2 \pm 6,9\end{array}$ & 0,000 & $\frac{15,05 \pm 1,5}{14,5 \pm 2,1}$ & $\begin{array}{c}0,00 \\
0\end{array}$ & $\begin{array}{l}26,9 \pm 4,2 \\
25,2 \pm 5,5\end{array}$ & $\begin{array}{c}0,00 \\
0\end{array}$ \\
\hline $\begin{array}{r}\text { Loa phát thanh: Có } \\
\text { Không }\end{array}$ & $\begin{array}{l}29,4 \pm 5,3 \\
28,0 \pm 6,1\end{array}$ & 0,001 & $\begin{array}{c}14,99 \pm 1,63 \\
14,8 \pm 1,62\end{array}$ & $\begin{array}{c}0,10 \\
7\end{array}$ & $\begin{array}{l}26,7 \pm 4,4 \\
26,5 \pm 5,7\end{array}$ & 0,65 \\
\hline Hàng xóm, người thân & $29,9 \pm 4,8$ & 0,00 & $15,08 \pm 1,5$ & 0,00 & $26,9 \pm 4,2$ & 0,03 \\
\hline
\end{tabular}




\begin{tabular}{|c|c|c|c|c|c|c|c|}
\hline \multirow{2}{*}{\multicolumn{2}{|c|}{$\begin{array}{lll} & & \text { Không } \\
\text { Khác: } & \text { Có } & \end{array}$}} & $27,7 \pm 6,4$ & \multirow{3}{*}{$\begin{array}{l}0 \\
0,00 \\
7\end{array}$} & $14,7 \pm 1,8$ & 0 & $26,5 \pm 4,8$ & \\
\hline & & $30,5 \pm 4,1$ & & $15,1 \pm 1,5$ & \multirow{2}{*}{$\begin{array}{c}0,18 \\
7\end{array}$} & $27,6 \pm 3,7$ & \multirow{2}{*}{$\begin{array}{c}0,02 \\
4\end{array}$} \\
\hline & Không & $29,0 \pm 5,6$ & & $14,9 \pm 1,65$ & & $26,6 \pm 4,5$ & \\
\hline
\end{tabular}

Theo bảng 14 cho thấy nguồn thông tin về dịch COVID-19 từ báo chí, truyền hình, internet, mạng xã hội, hàng xóm và người thân có liên quan đến kiến thức chung, thái độ chung và thực hành chung phòng, chống dịch COVID-19 $(p=0,000)$. Nguồn thông tin về dịch COVID-19 từ loa phát thanh chỉ có liên quan đến kiến thức chung, nhưng không có liên quan đến thái độ $(p=0,107)$ và thực hành chung $(p=0,65)$ phòng, chống dịch COVID-19.

Bảng 15. Môi liên quan giữa đặc điểm chung và thái độ chung phòng, chống dịch COVID-19

\begin{tabular}{|c|c|c|c|c|c|}
\hline \multirow{2}{*}{\multicolumn{2}{|c|}{ Đặc điểm chung }} & \multicolumn{4}{|c|}{ Thái độ chung $(\mathrm{N}=1.154)$} \\
\hline & & \multirow{3}{*}{$\begin{array}{c}\geq \mathbf{8 0} \% \\
461(89,7 \%) \\
585(91,4 \%)\end{array}$} & \multirow{3}{*}{$\begin{array}{c}\mathbf{6 0 - 7 9 \%} \\
41(8,0 \%) \\
42(6,6 \%)\end{array}$} & \multirow{3}{*}{$\begin{array}{c}<\mathbf{6 0} \% \\
12(2,3 \%) \\
13(2,0 \%)\end{array}$} & \multirow{3}{*}{$\begin{array}{c}\mathbf{p} \\
0,61\end{array}$} \\
\hline Giới & Nam & & & & \\
\hline & Nũ̃ & & & & \\
\hline \multirow[t]{5}{*}{ Nhóm tuối } & 18-29 tuối & $339(89,9 \%)$ & $32(8,5 \%)$ & $6(1,6 \%)$ & \multirow{5}{*}{0,18} \\
\hline & 30-39 tuổi & $402(91,6 \%)$ & $30(6,8 \%)$ & $7(1,6 \%)$ & \\
\hline & 40-49 tuối & $145(88,4 \%)$ & $12(7,3 \%)$ & $7(4,3 \%)$ & \\
\hline & 50-59 tuổi & $108(89,3 \%)$ & $8(6,6 \%)$ & $5(4,1 \%)$ & \\
\hline & Từ 60 tuối trở lên & $52(98,15)$ & $1(1,9 \%)$ & 0 & \\
\hline \multirow[t]{3}{*}{ Dân tộc } & Kinh & $545(94,8 \%)$ & $27(4,7 \%)$ & $3(0,5 \%)$ & \multirow{3}{*}{0,000} \\
\hline & $\hat{\mathrm{E}}$ đê & $385(84,4 \%)$ & $50(11 \%)$ & $21(4,6 \%)$ & \\
\hline & M'nông & $116(94,3 \%)$ & $6(4,9 \%)$ & $1(0,8 \%)$ & \\
\hline \multirow[t]{2}{*}{ Tôn giáo } & Có & $223(84,8 \%)$ & $29(11,0 \%)$ & $11(4,2 \%)$ & \multirow{2}{*}{0,001} \\
\hline & Không & $823(92,4 \%)$ & $54(6,1 \%)$ & $14(1,6 \%)$ & \\
\hline \multirow[t]{5}{*}{ Học vấn } & Không biết đọc, viết & $8(53,3 \%)$ & $1(6,7 \%)$ & $6(40 \%)$ & \multirow{5}{*}{0,000} \\
\hline & Cấp 1 & $72(80,9 \%)$ & $12(13,5 \%)$ & $5(5,6 \%)$ & \\
\hline & Cầp 2 & $296(86,5 \%)$ & $38(11,1 \%)$ & $8(2,3 \%)$ & \\
\hline & Cấp 3 & $298(92,8 \%)$ & $18(5,6 \%)$ & $5(1,6 \%)$ & \\
\hline & $\mathrm{TC}, \mathrm{CD}, \mathrm{DH}, \mathrm{S \boxminus H}$ & $372(96,1 \%)$ & $14(3,6 \%)$ & $1(0,3 \%)$ & \\
\hline \multirow[t]{6}{*}{ Nghề nghiệp } & Nông dân & $430(88,8 \%)$ & $40(8,3 \%)$ & $14(2,9 \%)$ & \multirow{6}{*}{0,003} \\
\hline & Công nhân & $137(85,1 \%)$ & $18(11,2 \%)$ & $6(3,7 \%)$ & \\
\hline & Sinh viên & $36(94,7 \%)$ & $1(2,6 \%)$ & $1(2,6 \%)$ & \\
\hline & CBVC & $260(97,4 \%)$ & $7(2,6 \%)$ & $0(0 \%)$ & \\
\hline & Lao động tự do & $125(89,3 \%)$ & $11(7,9 \%)$ & $4(2,9 \%)$ & \\
\hline & Khác & $58(90,6 \%)$ & $6(9,4 \%)$ & $0(0 \%)$ & \\
\hline \multirow{3}{*}{ Kinh tế hộ gia đình } & Nghèo, cận nghèo & $143(79,9 \%)$ & $21(11,7 \%)$ & $15(8,4 \%)$ & \multirow{3}{*}{0,000} \\
\hline & Trung bình & $797(92,7 \%)$ & $54(6,3 \%)$ & $9(1 \%)$ & \\
\hline & Trên trung bình & $106(92,2 \%)$ & $8(7,0 \%)$ & $1(0,9 \%)$ & \\
\hline \multirow{2}{*}{ Khu vực sống } & Thành thị & $181(97,3 \%)$ & $5(2,7 \%)$ & $0(0 \%)$ & \multirow{2}{*}{0,002} \\
\hline & Nông thôr & 865 & 7 & $25(2, \epsilon$ & \\
\hline
\end{tabular}

Theo bảng 15 cho thấy không có sự khác biệt giữa nam và nữ $(p=0,96)$, giữa các đô tuổi $(p=0,29)$ về thái độ chung về phòng, chổng dịch COVID-19. Có sự khác biệt thái độ chung về phòng, chống dịch COVID-19 với dân tộc $(p=0,000)$, tôn giáo $(p=0,001)$, trình độ học vấn $(p=0,000)$, nghề nghiệp ( $p=0,003)$, kinh tế hộ gia đình $(p=0,000)$ và khu vực sinh sống $(p=0,002)$.

Bảng 16. Mối liên quan giữa một số đặc điểm về tình trạng mắc COVID-19 với thái độ chung phòng chống dịch COVID-19

\begin{tabular}{|c|c|c|c|c|c|}
\hline \multirow{2}{*}{\multicolumn{2}{|c|}{ Tình trạng tiếp xúc COVID-19 }} & \multicolumn{4}{|c|}{ Thái độ chung $(\mathrm{N}=1.154)$} \\
\hline & & $\geq 80 \%$ & $60-79 \%$ & $<60 \%$ & $\mathbf{p}$ \\
\hline \multirow{2}{*}{ Đã mắc COVID-19 } & Có & $78(94 \%)$ & $4(4,8 \%)$ & $1(1,2 \%)$ & \multirow{2}{*}{0,55} \\
\hline & Không & $968(90,4 \%)$ & $79(7,4 \%)$ & $24(2,2 \%)$ & \\
\hline \multirow{2}{*}{ Gia đình có người mắc } & Có & $42(89,4 \%)$ & $5(10,6 \%)$ & $0(0 \%)$ & \multirow{2}{*}{0,39} \\
\hline & Không & $1004(90,7 \%)$ & $78(7 \%)$ & $25(2,3 \%)$ & \\
\hline \multirow{2}{*}{ Sống gân nhà người mắc } & Có & $99(93,4 \%)$ & $6(5,7 \%)$ & $1(0,9 \%)$ & \multirow{2}{*}{0,53} \\
\hline & Không & $947(90,4 \%)$ & $77(7,3 \%)$ & $24(2,3 \%)$ & \\
\hline
\end{tabular}




\section{Từng cách ly}

\begin{tabular}{|c|c|c|c|c|} 
Cách ly tâp trung & $76(93,8 \%)$ & $4(4,9 \%)$ & $1(1,2 \%)$ & \multirow{2}{*}{0,000} \\
\cline { 1 - 4 } Cách ly tại nhà & $131(81,4 \%)$ & $21(13 \%)$ & $9(5,6 \%)$ & \\
\hline Không & $839(92 \%)$ & $58(6,4 \%)$ & $15(1,6 \%)$ & \\
\hline
\end{tabular}

Theo bảng 16 cho thấy không có mối liên quan với thái độ chung phòng chống dịch COVID-19 giữa những người tham gia nghiên cứu về tình trạng mắc COVID-19 $(p=0,55)$, gia đình có người mắc COVID-19 $(p=0,39)$, sống gần nhà người mắc COVID-19 $(p=0,53)$. Có mối liên quan giữa những người tham gia nghiên cứu đã từng bị cách ly tập trung, cách ly tại nhà và không bị cách ly với thái độ chung phòng chống dịch COVID-19 $(p=0,000)$.

Bảng 17. Mối liền quan giữa đặc điểm chung và thực hành chung phòng, chống dịch COVID-19

\begin{tabular}{|c|c|c|c|c|c|}
\hline \multirow{2}{*}{\multicolumn{2}{|c|}{ Đặc điểm chung }} & \multicolumn{4}{|c|}{ Thực hành chung $(N=1.154)$} \\
\hline & & \multirow{2}{*}{$\begin{array}{c}\geq \mathbf{8 0} \% \\
340(66,1 \%)\end{array}$} & \multirow{2}{*}{$\begin{array}{c}\mathbf{6 0 - 7 9 \%} \\
137(26,7 \%)\end{array}$} & \multirow{2}{*}{$\begin{array}{c}<\mathbf{6 0 \%} \\
37(7,2 \%)\end{array}$} & \multirow{3}{*}{$\frac{\mathbf{P}}{0,028}$} \\
\hline Giới & Nam & & & & \\
\hline & Nữ & $463(72,3 \%)$ & $128(20 \%)$ & $49(7,7 \%)$ & \\
\hline \multirow[t]{5}{*}{ Nhóm tuối } & 18-29 tuối & $249(66 \%)$ & $97(25,7 \%)$ & $31(8,2 \%)$ & \multirow{5}{*}{0,5} \\
\hline & 30-39 tuối & $320(72,9 \%)$ & $95(21,6 \%)$ & $24(5,5 \%)$ & \\
\hline & 40-49 tuối & $115(70,1 \%)$ & $34(20,7 \%)$ & $15(9,1 \%)$ & \\
\hline & 50-59 tuối & $83(68,6 \%)$ & $27(22,3 \%)$ & $11(9,1 \%)$ & \\
\hline & Từ 60 tuối trở lên & $36(67,9 \%)$ & $12(22,6 \%)$ & $5(9,4 \%)$ & \\
\hline \multirow[t]{3}{*}{ Dân tộc } & Kinh & $455(79,1 \%)$ & $108(18,8 \%)$ & $12(2,1 \%)$ & \multirow{3}{*}{0,000} \\
\hline & Ė đê & $275(60,3 \%)$ & $124(27,2 \%)$ & $57(12,5 \%)$ & \\
\hline & M'nông & $73(59,3 \%)$ & $33(26,8 \%)$ & $17(13,8 \%)$ & \\
\hline \multirow[t]{2}{*}{ Tôn giáo } & Có & $160(60,8 \%)$ & $65(24,7 \%)$ & $38(14,4 \%)$ & \multirow[b]{2}{*}{0,000} \\
\hline & Không & $643(72,2 \%)$ & $200(22,4 \%)$ & $48(5,4 \%)$ & \\
\hline \multirow[t]{5}{*}{ Học vấn } & Không biết đọc & $3(20 \%)$ & $4(26,7 \%)$ & $8(53,3 \%)$ & \multirow{5}{*}{0,000} \\
\hline & Cấp 1 & $41(46,1 \%)$ & $28(31,5 \%)$ & $20(22,5 \%)$ & \\
\hline & Cấp 2 & $194(56,7 \%)$ & $111(32,5 \%)$ & $37(10,8 \%)$ & \\
\hline & Cấp 3 & $231(72 \%)$ & $76(23,7 \%)$ & $14(4,4 \%)$ & \\
\hline & $\mathrm{TC}, \mathrm{CD}, \mathrm{DH}, \mathrm{S} \boxminus \mathrm{H}$ & $334(86,3 \%)$ & $46(11,9 \%)$ & $7(1,8 \%)$ & \\
\hline \multirow[t]{6}{*}{ Nghề nghiệp } & Nông dân & $290(59,9 \%)$ & $142(29,3 \%)$ & $52(10,7 \%)$ & \multirow{6}{*}{0,000} \\
\hline & Công nhân & $96(59,6 \%)$ & $48(29,8 \%)$ & $17(10,6 \%)$ & \\
\hline & Sinh viên & $29(76,3 \%)$ & $8(21,1 \%)$ & $1(2,6 \%)$ & \\
\hline & CBVC & $239(89,5 \%)$ & $27(10,1 \%)$ & $1(0,4 \%)$ & \\
\hline & Lao động tự do & $101(72,1 \%)$ & $27(19,3 \%)$ & $12(8,6 \%)$ & \\
\hline & Khác & $48(75 \%)$ & $13(20,3 \%)$ & $3(4,7 \%)$ & \\
\hline \multirow{3}{*}{ Kinh tế hộ gia đình } & Nghèo, cận nghèo & $79(44,1 \%)$ & $59(33 \%)$ & $41(22,9 \%)$ & \multirow{3}{*}{0,000} \\
\hline & Trung bình & $630(73,3 \%)$ & $188(21,9 \%)$ & $42(4,9 \%)$ & \\
\hline & Trên trung bình & $94(81,7 \%)$ & $18(15,7 \%)$ & $3(2,6 \%)$ & \\
\hline \multirow{2}{*}{ Khu vực sống } & Thành thị & $154(82,8 \%)$ & $30(16,1 \%)$ & $2(1,1 \%)$ & \multirow[b]{2}{*}{0,000} \\
\hline & Nông thôn & $649(67 \%)$ & $235(24,3 \%)$ & $84(8,7 \%)$ & \\
\hline
\end{tabular}

Theo bảng 17 cho thấy không có sự khác biệt giữa nam và nữ $(p=0,028)$, giữa các độ tuổi $(p=0,5)$ về thực hành chung về phòng, chống dịch COVID-19. Có sự khác biệt thực hành chung về phòng, chống dịch COVID-19 với dân tộc $(p=0,000)$, tôn giáo $(p=0,000)$, trình độ học vấn $(p=0,000)$, nghề nghiệp $(p=0,000)$, kinh tế hộ gia đình $(p=0,000)$ và khu vực sinh sống $(p=0,000)$.

Bảng 18. Mối liên quan giữa một số đặc điểm về tình trạng măc COVID-19 với thực hành chung phòng chống dịch COVID-19

\begin{tabular}{|c|c|c|c|c|c|}
\hline \multirow{2}{*}{\multicolumn{2}{|c|}{ Tình trạng tiếp xúc COVID-19 }} & \multicolumn{4}{|c|}{ Thực hành chung $(\mathrm{N}=1.154)$} \\
\hline & & $\geq 80 \%$ & $60-79 \%$ & $<60 \%$ & $\mathbf{p}$ \\
\hline \multirow{2}{*}{ Đã mắc COVID-19 } & $\mathrm{C}$ & $54(65,1 \%)$ & $24(28,9 \%)$ & $5(6 \%)$ & \multirow{2}{*}{0,39} \\
\hline & Không & $749(69,9 \%)$ & $241(22,5 \%)$ & $81(7,6 \%)$ & \\
\hline \multirow{2}{*}{ Gia đình có người mắc } & Có & $26(55,3 \%)$ & $19(40,4 \%)$ & $2(4,3 \%)$ & \multirow[b]{2}{*}{0,013} \\
\hline & Không & $777(70,2 \%)$ & $246(22,2 \%)$ & $84(7,6 \%)$ & \\
\hline \multirow{2}{*}{ Sống gân nhà người mắc } & $\mathrm{C}$ & $67(6$ & $31(29,2 \%)$ & $8(7,5 \%)$ & \multirow{2}{*}{0,26} \\
\hline & Không & $736(70,2 \%)$ & $234(22,3 \%)$ & $78(7,4 \%)$ & \\
\hline
\end{tabular}




\begin{tabular}{|c|c|c|c|c|c|}
\hline \multirow{2}{*}{ Từng cách ly } & Cách ly tâp trung & $55(67,9 \%)$ & $22(27,2 \%)$ & $4(4,9 \%)$ & \multirow{2}{*}{0,000} \\
\cline { 2 - 6 } & Cách ly tại nhà & $95(59 \%)$ & $38(23,6 \%)$ & $28(17,4 \%)$ & \multirow{2}{*}{ ly (5,9\%) } \\
\hline & Không & $653(71,6 \%)$ & $205(22,5 \%)$ & $54(5,9 \%$ \\
\hline
\end{tabular}

Theo bảng 18 cho thấy không có mối liên quan với thực hành chung phòng chống dịch COVID-19 giữa những người tham gia nghiên cứu về tình trạng mắc COVID-19 $(p=0,39)$, gia đình có người mắc COVID-19 $(\mathrm{p}=0,013)$, sống gần nhà người mắc COVID-19 $(p=0,26)$. Có mối liên quan giữa những người tham gia nghiên cứu đã từng bị cách ly tập trung, cách ly tại nhà và không bị cách ly với thái độ chung phòng chống dịch COVID-19 $(p=0,000)$.

Bảng 19. Mối tương quan giữa kiến thức chung với thái độ chung và thức hành chung về phòng chống dịch COVID-19 $(N=1.154)$

\begin{tabular}{|c|c|c|c|c|}
\hline \multirow{2}{*}{$\begin{array}{c}\text { Hệ số tương } \\
\text { quan Pearson }\end{array}$} & \multicolumn{2}{|c|}{$\begin{array}{c}\text { Thái độ } \\
\text { chung }\end{array}$} & \multicolumn{2}{c|}{$\begin{array}{c}\text { Thực hành } \\
\text { chung }\end{array}$} \\
\cline { 2 - 5 } & $\mathbf{r}$ & $\mathbf{p}$ & $\mathbf{r}$ & $\mathbf{p}$ \\
\hline $\begin{array}{c}\text { Kiến thức } \\
\text { chung }\end{array}$ & 0,4 & 0,0 & 0,60 & 0,00 \\
\hline
\end{tabular}

Bảng 19 cho thấy mối tương quan thuận giữa kiến thức chung với thái độ chung $(r=0,490$, $\mathrm{N}=1.154$ và $\mathrm{p}=0,000$ ) và thực hành chung $(r=0,601, N=1.154, p=0,000)$ về phòng chống dịch COVID-19.

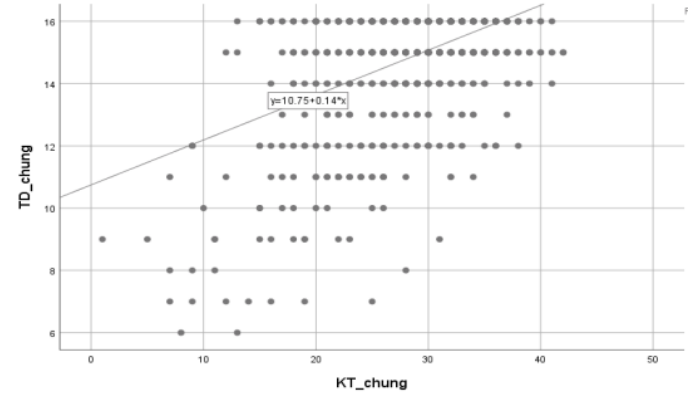

Hình 1. Môi tương quan thuận giữa kiến thức chung với thái độ chung ( $r=0,490$, $N=1.154$ và $p=0,000$ ).

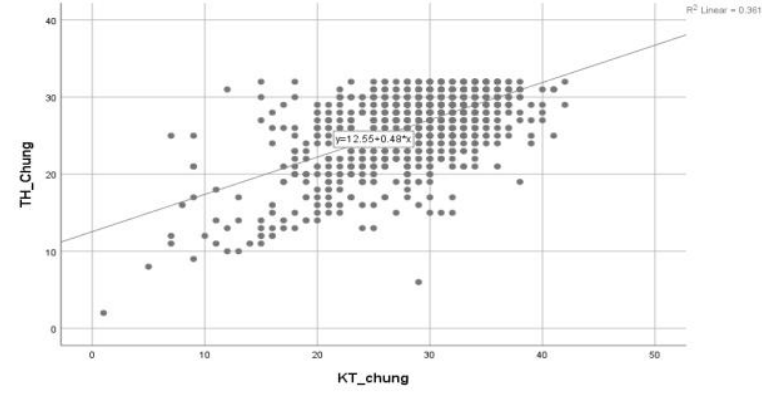

Hình 2. Môi tương quan thuận giữa kiến thức chung với thức hành chung $(r=0,601$, $N=1.154, p=0,000)$
Bảng 20. Môi tương quan giữa thái độ chung với thức hành chung về phòng chống dịch COVID-19 ( $N=1.154)$

\begin{tabular}{|c|c|c|}
\hline \multirow{2}{*}{$\begin{array}{c}\text { Hệ số tương quan } \\
\text { Pearson }\end{array}$} & \multicolumn{2}{|c|}{$\begin{array}{c}\text { Thực hành } \\
\text { chung }\end{array}$} \\
\cline { 2 - 3 } & $\mathbf{r}$ & $\mathbf{p}$ \\
\hline Thái độ chung & 0,545 & 0,000 \\
\hline
\end{tabular}

Bảng 20 cho thấy mối tương quan thuận giữa thái độ chung với thực hành chung $(r=0,545$, $n=1.154, p=0,000$ ) về phòng chống dịch COVID-19.

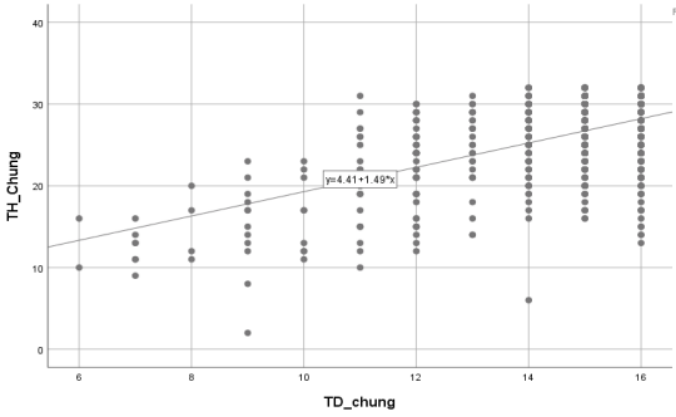

Hình 3. Môi tương quan thuận giữa thái độ chung với thức hành chung $(r=0,545, N=1.154, p=0,000)$.

\section{BÀN LUÂN}

Kết quả nghiên cứu trên 1.154 người trên 18 tuổi về kiến thức, thái độ, thực hành phòng, chống dịch COVID-19 ở tỉnh Đắk Lắk cho thấy về đặc điểm của mẫu nghiên cứu có $44,5 \%$ là nam giới và $55,5 \%$ là nữ giới tham gia vào nghiên cứu này, tương tự về nữ giới $(54,8 \%)$ trong nghiên cứu tại Đại học Y Dược thành phố Hồ Chí Minh [6]. Độ tuổi trung bình là 35,9 $\pm 11,9$ ( nhỏ nhất là 18 và lớn nhất là 92 tuổi), trong đó nhóm tuổi từ 30-39 tuổi chiếm cao nhất là 38\%. Độ tuổi trung bình này cũng tương tự một nghiên cứu ở Iran là $34,37 \pm 11,25$ tuổi [7]. Phân bố theo dân tộc thì dân tôc Kinh chiếm $49,8 \%$, Ê Đê chiếm $39,5 \%$ và M'Nông là $10,7 \%$. Có $77,2 \%$ người tham gia nghiên cứu không theo tôn giáo nào. Trình độ học vấn chủ yếu từ cấp 2 trở lên, cao nhất ở trình độ trung cấp, cao đẳng, đại học là 33,5\% nhưng thấp hơn trình độ học vấn từ trung cấp trở lên $(59,8 \%)$ trong nghiên cứu tại Đại học Y Dược thành phố Hồ Chí Minh [6]. Nghề nghiệp của nhóm tham gia nghiên cứu chủ yếu là nông dân chiếm $41,9 \%$. Có 74,5\% người tham gia nghiên cứu có kinh tế hộ gia đình ở mức trung bình. Có 83,9\% người tham gia nghiên cứu ở khu vực nông thôn và 
16,1\% ở khu vực thành thị. Phân bố khu vực sinh sống của người tham gia nghiên cứu phù hợp với khu vực nông thôn $(82,6 \%)$ và thành thị $(17,4 \%)$ ở tỉnh Đắk Lắk [8].

Có 99,39\% người tham gia nghiên cứu đã được nghe nói về dịch COVID -19. Thông tin về dịch COVID-19 chủ yếu từ các nguồn: $87,8 \%$ từ báo chí, truyền hình; $86,3 \%$ từ internet, mạng xã hội; $84,4 \%$ từ cán bộ y tế và loa phát thanh $82,8 \%$. Thông tin về dịch COVID-19 từ các nguồn báo chí, truyền hình và từ internet, mạng xã hội của chúng tôi cao hơn nguồn báo chí $(57,1 \%)$, truyền hình $(75,2 \%)$ và internet $(72,2 \%)$ trong nghiên cứu tại Đại học Y Dược thành phố Hồ Chí Minh [6]. Nguồn thông tin về dịch COVID-19 của chúng tôi chủ yếu cũng phù hợp với thông tin người dân nhận được chủ yếu từ internet hoặc các phương tiện truyền thông công cộng trong nghiên cứu của Bệnh viện Nguyễn Tri Phương ở Thành phố Hồ Chí Minh [9].

Nghiên cứu đã chỉ ra có $6,5 \%$ người tham gia nghiên cứu có kiến thức tốt và $68,7 \%$ người tham gia nghiên cứu có kiến thức trung bình khá về phòng chống dịch COVID -19. Kết quả của chúng tôi thấp hơn nhiều so với nghiên cứu tại Đại học Y Dược thành phố Hồ Chí Minh có tới $93,7 \%$ người tham gia nghiên cứu có kiến thức tốt và $5,5 \%$ người tham gia nghiên cứu có kiến thức trung bình khá về phòng chống dịch COVID -19 [6]. Trong nghiên cứu của chúng tôi có $90,6 \%$ người tham gia nghiên cứu có thái độ chung tích cực phòng chống dịch COVID-19. Kểt quả của chúng tôi cao hơn nhiều so với nghiên cứu tại Đại học Y Dược thành phố Hồ Chí Minh chỉ có $76,3 \%$ người tham gia nghiên cứu có thái độ tích cực về phòng chống dịch COVID -19 [6]. Theo bảng 8 cho thấy có $69,5 \%$ người tham gia nghiên cứu có thực hành đúng phòng chống dịch COVID-19. Kết quả của chúng tôi cao hơn so với nghiên cứu tại Đại học Y Dược thành phố Hồ Chí Minh chỉ có $57,7 \%$ người tham gia nghiên cứu có thực hành đúng về phòng chống dịch COVID -19 [6]

Theo bảng 11 cho thấy chỉ có $35,1 \%$ có thái độ tích cực về sử dụng thảo dược và y học cổ truyền, $52,9 \%$ việc hạn chế đi làm tại cơ quan, $73 \%$ về uống bổ sung Vitamin C, 73,7\% tập thế dục rèn luyện sức khỏe và $75,9 \%$ có thái độ tích cực về vệ sinh tay. Kết quả của chúng tôi cao hớn so với nghiên cứu tại Đại học Y Dược thành phố Hồ Chí Minh có $71,2 \%$ người tham gia nghiên cứu có thực hành tích cực về vệ sinh tay về phòng chống dịch COVID -19 [6] và Bệnh viện nhân dân 115 (72,4\%) ở Tp.Hồ Chí Minh.
Bảng 19 cho thấy mối tương quan thuận giữa kiến thức chung với thái độ chung $(r=0,490$, $\mathrm{n}=1.154$ và $\mathrm{p}=0,000$ ) và thực hành chung $(r=0,601, n=1.154, p=0,000)$ về phòng chống dịch COVID-19 cũng như bảng 20 cho thấy mối tương quan thuận giữa thái độ chung với thực hành chung $(r=0,545, n=1.154, p=0,000)$ về phòng chống dịch COVID-19. Kết quả nghiên cứu này cũng phù hợp với mối liên quan giữa kiến thức và thái độ trong nghiên cứu tại Đại học $\mathrm{Y}$ Dược thành phố Hồ Chí Minh [6].

\section{KẾT LUÂ̂N}

- Có 44,5\% nam giới và $55,5 \%$ là nữ giới. Độ tuổi trung bình là $35,9 \pm 11,9$ tuổi. Dân tộc Kinh chiếm 49,8\%, Ê Đê chiếm 39,5\% và M'Nông là $10,7 \%$. Có $77,2 \%$ người không theo tôn giáo nào. Trình độ học vấn chủ yếu từ cấp 2 trở lên. $41,9 \%$ có nghề nghiệp là nông dân. $74,5 \%$ có kinh tế hộ gia đình ở mức trung bình. Có $83,9 \%$ ở khu vực nông thôn và $16,1 \%$ ở khu vực thành thị. Có $7,2 \%$ người tham gia nghiên cứu đã mắc COVID-19 và 4,1\% trong gia đình đã hoặc đang có người bị mắc COVID-19.

- Có 99,39\% người tham gia nghiên cứu đã được nghe nói về dịch COVID -19. Kênh tiếp nhận thông tin về dịch COVID-19 chủ yếu từ các nguồn: $87,8 \%$ từ báo chí, truyền hình; $86,3 \%$ từ internet, mạng xã hội; $84,4 \%$ từ cán bộ y tế và loa phát thanh $82,8 \%$.

- Điểm trung bình chung của kiến thức là $29,16 \pm 5,5$ trên tổng số 45 điểm. Nhưng trả lời kiến thức đúng về các triệu chứng của bệnh COVID-19 chỉ có $8,1 \%$, bệnh COVID-19 lây truyền qua đường nào là $13,3 \%$, bệnh COVID-19 nguy hiểm hơn và có thể tử vong là $53,9 \%$, người mắc COVID-19 lây truyền bệnh là $56,1 \%$ và những biện pháp giúp phòng ngừa mắc COVID-19 là $55,7 \%$.

- Điểm trung bình chung của thái độ là 14,95 $\pm 1,6$ trên tổng số điểm là 16 . Có $90,6 \%$ người tham gia nghiên cứu có thái độ chung tích cực phòng chống dịch COVID-19. Có 59,4\% người tham gia nghiên cứu có thái độ lo sợ dịch COVID-19.

- Điểm trung bình chung của thực hành là $26,7 \pm 4,5$ trên tổng số điểm là 32. Có $69,5 \%$ thực hành đúng phòng chống dịch COVID-19. Chỉ có $35,1 \%$ có thực hành tích cực về sử dụng thảo dược và y học cổ truyền, $52,9 \%$ việc hạn chế đi làm tại cơ quan, $73 \%$ về uống bổ sung Vitamin $C, 73,7 \%$ tập thể dục rèn luyện sức khỏe và $75,9 \%$ có thái độ tích cực về vệ sinh tay.

- Không có sự khác biệt giữa nam và nữ $(p=$ 
$0,96)$, giữa các độ tuổi $(p=0,29)$ về kiến thức chung, thái độ chung và thực hành chung về phòng, chống dịch COVID-19.

- Có sự khác biệt kiến thức chung, thái đô chung và thực hành chung về phòng, chống dịch COVID-19 với dân tộc $(p<0,01)$, tôn giáo $(p<0,01)$, trình độ học vấn $(p<0,01)$, nghề nghiệp $(p<0,01)$, kinh tế hộ gia đình $(p<0,01)$ và khu vực sinh sống $(p<0,01)$.

- Nguồn thông tin về dịch COVID-19 từ báo chí, truyền hình, internet, mạng xã hội, hàng xóm và người thân có liên quan đến kiến thức chung, thái độ chung và thực hành chung phòng, chống dịch COVID-19 $(p=0,000)$. Nguồn thông tin về dịch COVID-19 từ loa phát thanh chỉ có liên quan đến kiến thức chung $(p=0,001)$.

- Có mối tương quan thuận giữa kiến thức chung với thái độ chung $(r=0,490, N=1.154$ và $\mathrm{p}=0,000)$ và thực hành chung $(\mathrm{r}=0,601$, $\mathrm{N}=1.154, \mathrm{p}=0,000$ ) về phòng chống dịch COVID19. Có mối tương quan thuận giữa thái độ chung với thực hành chung $(r=0,545, n=1.154$, $\mathrm{p}=0,000$ ) về phòng chống dịch COVID- 19 .

\section{TÀI LIÊU THAM KHẢO}

1. Bộ Y tế. Quyết định số 3638/Q⿹-BYT ngày 30 tháng 07 năm 2021 của Bộ Y tế về việc ban hành "hướng dẫn tạm thời giám sát và phòng, chống COVID-19"

2. Sở Y tế Đắk Lắk. Báo cáo nhanh số 819/BC-SYT ngày 07/12/2021 của Sở Y tế Đắk Lắk về tình hình phòng, chống dịch COVID-19 trên địa bản tỉnh Đắk Lắk.

3. Yimer $M$, Abera B, Mulu W, Bezabih B. Knowledge, attitude and practices of high risk populations on louse-borne relapsing fever in Bahir Dar city, north-west Ethiopia. Sci J Public Health. 2014;2(1):15-22. doi:10.11648/j.sjph.20140201.13

4. Koo H-C, Poh B, Ruzita A. Assessment of knowledge, attitude and practice towards whole grains among children aged 10 and 11 years in Kuala Lumpur. Int J Food Sci Nutr Diet. 2015; 4(1):171-177.doi:10.19070/2326-3350-1500032

5. Seid MA, Hussen MS. Knowledge and attitude towards antimicrobial resistance among final year undergraduate paramedical students at University of Gondar, Ethiopia. BMC Infect Dis. 2018;18(1):312. doi:10.1186/s12879-018-3199-1

6. Hoang Bac Nguyen, Thi Hong Minh Nguyen, Thi Thanh Tam Tran, Thi Hong Nhan Vo, Van Hung Tran, Thi Nam Phuong Do, Quang Binh Truong, Thi Hiep Nguyen, and Loan Khanh Ly. Knowledge, Attitudes, Practices, and Related Factors Towards COVID-19 Prevention Among Patients at University Medical Center Ho Chi Minh City, Vietnam. https://www.ncbi.nlm.nih.gov/pmc/articles/PMC81 63721/\#cit0017. Truy cập ngày 22/11/2021.

7. Amirhossein Erfani, Reza Shahriarirad, Keivan Ranjbar, Alireza Mirahmadizadeh \& Mohsen Moghadami. Knowledge, Attitude and Practice toward the Novel Coronavirus (COVID-19) Outbreak: A Population-Based Survey in Iran. https://www.who.int/bulletin/online first/20256651.pdf. Truy cập ngày 23/11/20021.

8. Cổng thông tin điên tử tỉnh Đắk Lắk. https://daklak.gov.vn/tong-quan-dak-lak//asset_publisher/bDngMUmMrWIw/content/i-ieukien-tu-nhien. Trưy cập ngày 24/11/2021.

9. Bệnh viện Nguyễn T̛ri Phương. Khảo sát sư hiểu biết về COVID-19 của người dẫn đến khám chữa bệnh tại bệnh viện Nguyễn Tri Phương. https://bvnguyentriphuiong.com.vn/nghien-cuunoi-bo-va-dang-tai-tap-chi-trong-nuoc/khao-sat-suhieu-bietkhao-sat-su-hieu-biet-ve-covid-19-cuanguoi-dan-den-kham-chua-benh-tai-benh-viennguyen-tri-phuong-ve-covid-19-cua-nguoi-danden-kham-chua-benh-tai-benh-vien-nguyen-triphuong. Truy cập ngày 25/11/2021.

\section{ĐĂC ĐIỂM LÂM SÀNG TIC ÂM THANH Ở HộI CHỨNG TOURETTE}

\section{TÓM TẮT}

Nghiên cứu rối loạn Tic ở trẻ có hội chứng Tourette với mục tiêu mô tả đặc điểm lâm sàng Tic âm thanh ở trẻ được chẩn đoán mắc hội chứng Tourette bằng phương pháp mô tả cắt ngang ở 77 trẻ đến khám lần đâu tiên tại phòng khám chuyên khoa Tâm thần, Bệnh viện Nhi Trung ương, có tuổi dưới 18 , được chẩn đoán

\section{${ }^{1}$ Dai họ Y Hà Nôi}

2 Viện Sức Khỏe Tâm Thần - Bệnh Viện Bạch Mai

Chịu trách nhiệm chính: Dương Minh Tâm

Email: duongminhtam@hmu.edu.vn

Ngày nhận bài: 22.10.2021

Ngày phản biện khoa học: 20.12.2021

Ngày duyệt bài: 28.12.2021

\section{Trần Nguyễn Ngọc ${ }^{1,2}$, Dương Minh Tâm ${ }^{1,2}$}

xác định hội chứng Tourette (F95.2) theo tiêu chuẩn chẩn đoán của ICD 10. Kết quả: phân lớn các động tác tic âm thanh khởi phát khi trẻ dưới 7 tuổi: $62,3 \%$, chỉ có $1,3 \%$ trẻ khởi phát ở tuổi trên 11 . Phân lớn bệnh nhân nhâan được chẩn đoán hội chứng Tourette ở lứa tuổi $8-11$ (55,8\%). Các triêu chứng tic âm thanh đơn giản xuất hiện đa dang: hắng giọng là biểu hiện gặp nhiêu nhất, nhiều hơn rõ rệt so với các biểu hiện khác: $66,2 \%$ ); tiếp theo khit mũi: $18,2 \%$ và khac: $15,6 \%$. Chỉ có 3 triệu chứng Tic âm thanh phức tạp xuất hiện, đó là: nói tục: $2,6 \%$; nói lắp bắp:2,6\% và phát âm không rõ: $1,3 \%)$. Kết luận: Phát hiện sớm các triệu chứng tic âm thanh là điều quan trong trong chẩn đoán chính xác hội chứng Tourette, để từ đó bệnh nhân có thể được điều trị kịp thời.

Tư' khoá: hội chứng Tourette; Tic âm thanh; trẻ em. 